This item was submitted to Loughborough's Research Repository by the author.

Items in Figshare are protected by copyright, with all rights reserved, unless otherwise indicated.

\title{
Laser sintered body armour - establishing guidelines for dual-layered stab protection
}

PLEASE CITE THE PUBLISHED VERSION

http://dx.doi.org/10.1504/IJRAPIDM.2015.073545

\section{PUBLISHER}

(C) Inderscience

\section{VERSION}

AM (Accepted Manuscript)

\section{PUBLISHER STATEMENT}

This work is made available according to the conditions of the Creative Commons Attribution-NonCommercialNoDerivatives 4.0 International (CC BY-NC-ND 4.0) licence. Full details of this licence are available at: https://creativecommons.org/licenses/by-nc-nd/4.0/

\section{LICENCE}

CC BY-NC-ND 4.0

\section{REPOSITORY RECORD}

Johnson, Andrew, Guy Bingham, and Candice E. Majewski. 2015. "Laser Sintered Body Armour - Establishing Guidelines for Dual-layered Stab Protection”. Loughborough University. https://hdl.handle.net/2134/19495. 


\title{
Laser Sintered body armour - establishing guidelines for dual-layered stab protection
}

\author{
A.A. Johnson* and G.A. Bingham \\ Loughborough Design School \\ Loughborough University \\ Leicestershire \\ LE11 3TU \\ United Kingdom \\ Email: a.johnson@1boro.ac.uk \\ Email: g.a.bingham@lboro.ac.uk \\ *Corresponding author \\ C.E. Majewski \\ Department of Mechanical Engineering \\ The University of Sheffield \\ Sheffield \\ S10 2TN \\ United Kingdom
}

Email: c.majewski@sheffield.ac.uk

\begin{abstract}
:
Additive Manufacturing technologies are increasingly being utilised in a range of custom and high performance applications. Initial research has demonstrated the successful use of Laser Sintering for achieving stab protection to UK body armour standards. However, further development is required to establish a comprehensive set of stab resistant design characteristics which could be used for the generation of a bespoke AM body armour garment. This body of work is a precursor to such developments, instead establishing the foundations as to whether dual layered Laser Sintered planar structures can be used to minimise body armour thickness requirements, whilst maintaining successful stab protection to internationally recognised standards.
\end{abstract}

Keywords: Additive Manufacturing; Body Armour; Laser Sintering; Stab Resistance; Home Office Scientific Development Branch; 


\section{Introduction}

Throughout history the primary objective of any body armour solution has been to protect its wearer from sustaining life threatening injuries (Ashdown, 1909). Historically such solutions comprised of animal hide construction, while more recent solutions include the use of moulded Polycarbonate, and complex aramid fibres (Kaiser, 2013; Scott, 2005). Although these solutions meet modern protective standards, they continue to present a number of issues which have been shown to impair the operational performance of its wearer - including but not exclusive to poor thermal regulation and reduced operational manoeuvrability (Dempsey et al., 2013).

Additive Manufacturing (AM) technologies are increasingly being utilised for a range of novel applications from customised clothing to use in high performance industrial environments (Bingham et al., 2013; Continuum Fashion, 2011; Krassenstein, 2015). By utilising the high degree of design freedom offered by such technologies, there is the potential to manufacture highly protective solutions with enhanced benefits to its wearer such as highly customised protective armour with improved operational manoeuvrability and comfort. By utilising one or multiple AM technologies for the fabrication of armour, there is the potential to integrate a range of technical features to optimise the operational performance of its wearer (Johnson, 2014; Johnson et al., 2013).

Previous research has identified the suitability of Additive Manufacturing for the manufacture of components capable of achieving stab protection to the UK Home Office Scientific Development Branch's (HOSDB) body armour standard (Johnson, 2014; Johnson et al., 2013, 2012). Such research determined that a minimum single thickness planar 
specimen of $11.00 \mathrm{~mm}$, manufactured from Duraform EX® Laser Sintering (LS) powder, was required to provide stab protection to the UK HOSDB KR1-E1 protection level (Johnson, 2014).

Although a significant step in utilising AM technologies for the manufacture of personalised body armour, further development was required to establish guidelines for the manufacture of armour that features overlapping or articulating elements. Existing research has specifically focussed on the manufacture of single thickness Laser Sintered specimens. However, a wide range of protective mechanisms, featured within both naturally occurring and engineered armours, have successfully demonstrated the use of multi-layered structures aimed at providing protection against a multitude of threat levels whilst minimising overall armour thickness (Ben-Dor et al., 2010; Johnson, 2014; Teng et al., 2008; Zhu et al., 2012). Therefore, the primary objective of this experiment was to assess the stab resistant performance of dual-layered Laser Sintered specimens manufactured from Duraform EX® powder - with the aim to minimise the overall thickness required to provide protection to the HOSDB KR1-E1 stab resistance level. 


\section{Experimental methodology}

Previous research has identified that Laser Sintered specimens featuring a 50/50 mix of virgin and recycled powder exhibited greater levels of stab resistance over $100 \%$ virgin alternatives (Johnson, 2014; Johnson et al., 2013). All test specimens were therefore manufactured from 3D Systems ${ }^{\mathrm{TM}}$ Duraform EX® using a 50/50 mix of recycled and virgin powder, and built using an EOS P100 Formiga Laser Sintering machine. Previously established process parameters were used and are identified within Table 1.

Table 1: Laser sintering process parameters

\begin{tabular}{lc}
\hline Parameter & Duraform EX® (50/50 mix) \\
\hline Layer thickness & $0.1 \mathrm{~mm}$ \\
\hline Part bed temperature & $178.5^{\circ} \mathrm{C}$ \\
\hline Laser Power & $22 \mathrm{~W}$ \\
\hline Scan Speed & $3,000 \mathrm{~mm} / \mathrm{s}(3.0 \mathrm{~m} / \mathrm{s})$ \\
Warm-up time & 300 minutes \\
\hline
\end{tabular}

Following extensive testing, these parameters were previously identified as the most suitable for processing the selected powder combinations (Johnson, 2014). Too short of a warmup time or too high a laser scan speed, could have resulted in the manufacturing failure of test specimens. The optimised parameters documented within Table 1 ensured the successful manufacture of specimens for experimental testing. Two sets of experiments were performed within this body of research and are outlined in the proceeding sub-sections.

\subsection{Build location}

To minimise any potential effects on the stab resistant performance of the test specimens due 
to positioning within the build chamber, the placement of each specimen was randomised across both experimental groups. An example of the specimen placement within the build chamber is shown within Figure 1.

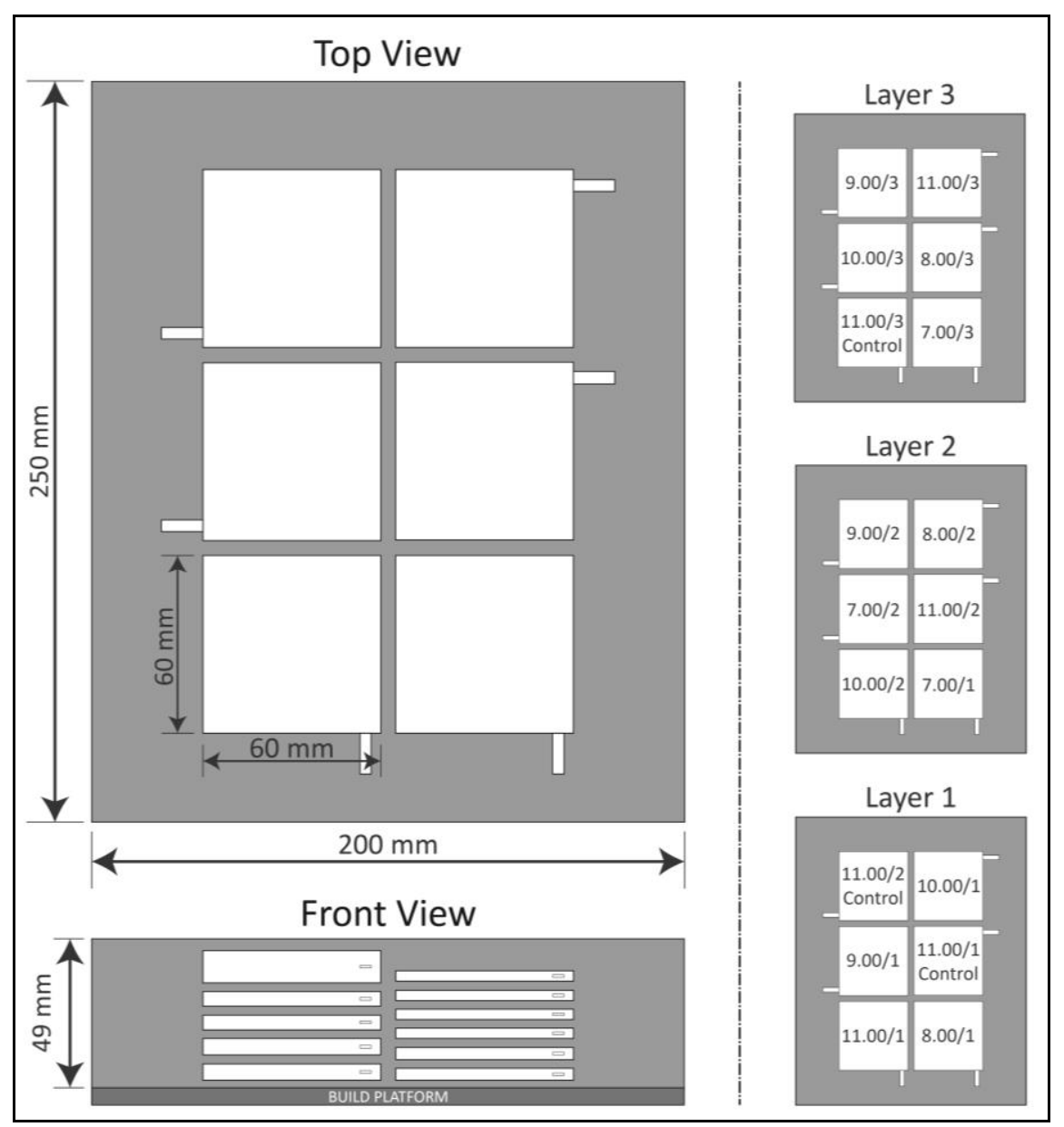

Figure 1: Specimen build location

Specimens were centrally located within the $200 \times 250 \mathrm{~mm}$ build platform of the EOS P100 Formiga LS machine. A $3.00 \mathrm{~mm}$ thick powder base was applied to the platform during build preparation, with a further $2.00 \mathrm{~mm}$ 's of powder applied during the machine 
warm-up phase. A spacing of $5.00 \mathrm{~mm}$ between specimens was maintained throughout in both $\mathrm{X}$ and $\mathrm{Y}$-directions, while a $3.00 \mathrm{~mm}$ spacing between specimens was established in the Z-direction.

Upon completion of the build and to control cooling of the built specimens, a 5.00 mm thick layer of power was applied to the top of the build volume - creating a total build height of $49 \mathrm{~mm}$ for experiment one, and $127 \mathrm{~mm}$ for experiment two.

A detailed procedure for the preparation of the CAD build files, steps taken to initiate the LS build, and for the post-processing of specimens was established (Johnson, 2014). Minimal post-processing activities were performed to ensure only non-sintered powder was removed - thus safeguarding against specimen damage during cleaning activities.

\subsection{Experiment one: equal thickness specimens}

Specimens measured $60 \times 60 \mathrm{~mm}$ (length and width), and ranged in total thickness from 7.00 $\mathrm{mm}$ to $11.00 \mathrm{~mm}$ - increasing in $1.00 \mathrm{~mm}$ increments. Each test specimen comprised of two equal thickness planar bodies to create a dual layered test structure - as shown within Figure 2. 


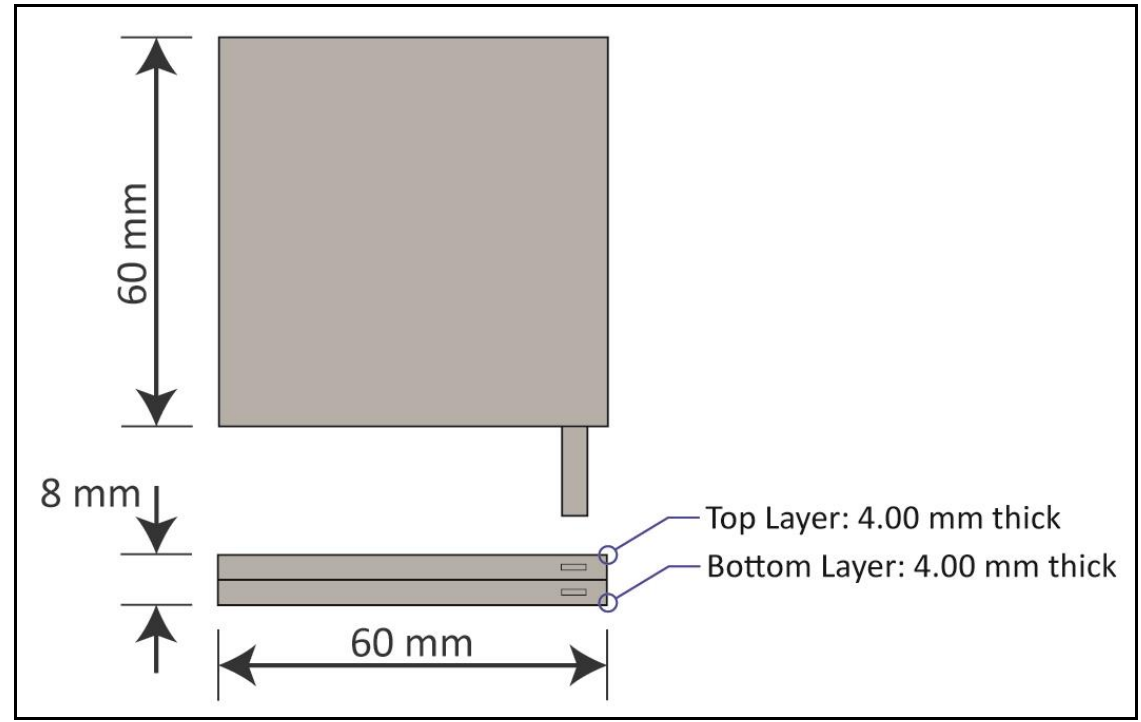

Figure 2: Example - $8.00 \mathrm{~mm}$ thick dual layered specimen $(2$ x $4.00 \mathrm{~mm}$ planar bodies $)$

The stab protective performance of five thickness groups was assessed, with three dual layered test specimens per group. In total a series of 15 dual layered test specimens were manufactured, with a further three $11.00 \mathrm{~mm}$ single thickness scientific control specimens also generated.

\subsection{Experiment two: multi-thickness specimens}

To support the validity of the results gathered from the first experiment, further testing was performed using dual layered specimens that featured two multi-thickness planar bodies. This experiment was performed to determine whether appropriate stab protection could be maintained if the minimum dual layered thickness, as established within Experiment one, could be constructed from two planar bodies of differing thicknesses. By determining the effect of such, the design of an individual protective element could be tailored. For example, 
protective elements in one region may feature two equal thickness protective bodies, whilst their thickness becomes graduated towards featuring a thinner top layer within a nearby region. The development of such may be for operational or practical benefits - further investigation would be required.

All specimens measured $60 \times 60 \mathrm{~mm}$, and comprised of a total thickness of $9.00 \mathrm{~mm}$ with individual planar bodies ranging in thickness from $1.00 \mathrm{~mm}$ to $8.00 \mathrm{~mm}$ in $0.50 \mathrm{~mm}$ increments. For example, a $2.50 \mathrm{~mm}$ top layer and a $6.50 \mathrm{~mm}$ bottom layer would create a 9.00 thick dual layered specimen - as depicted within Figure 3.

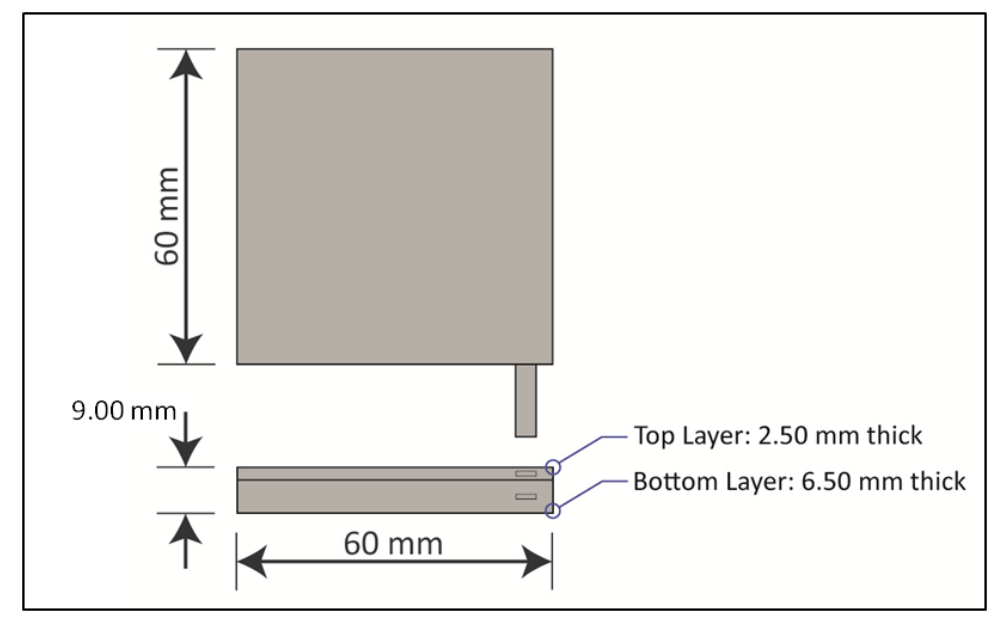

Figure 3: Experiment two - multi-thickness specimens

In total 15 dual layer combinations were tested with three specimens per combination - a total of 45 test specimens were manufactured.

\subsection{Stab test experimental design}

Based on the results from previous experimentation, all stab tests featured use of the Stanley 
1992 trimming blade (Johnson, 2014). To minimise the effects of any uncontrollable variables across both experiments, the order in which the specimens were stab tested was randomised. Dual layered specimens were placed directly on top of each other, and appropriately positioned to enable the test blade to contact the strike surface of the top specimen within its central region.

\subsection{Stab test methodology}

Within the UK, all stab resistant body armour used by Police officers must be certified against the Home Office Scientific Development Branch's (HOSDB) knife resistant (KR) standards. Three levels of stab resistance exist, including: (Croft and Longhurst, 2007a)

- KR1: For armour use in low threat situations - tested to 24 Joules of stab impact energy.

- KR2: Providing medium protection as general duty armour - tested to 33 Joules of stab impact energy.

- KR3: Providing protection in high threat level environments - tested to 43 Joules of stab impact energy.

The following subsections document the methodology and apparatus used during the stab testing of the manufactured specimens in line with UK HOSDB KR1 stab impact energy. 


\subsubsection{Drop tower apparatus}

All stab tests were performed using an 'Instron 9250HV' instrumented drop tower, as shown within Figure 4.

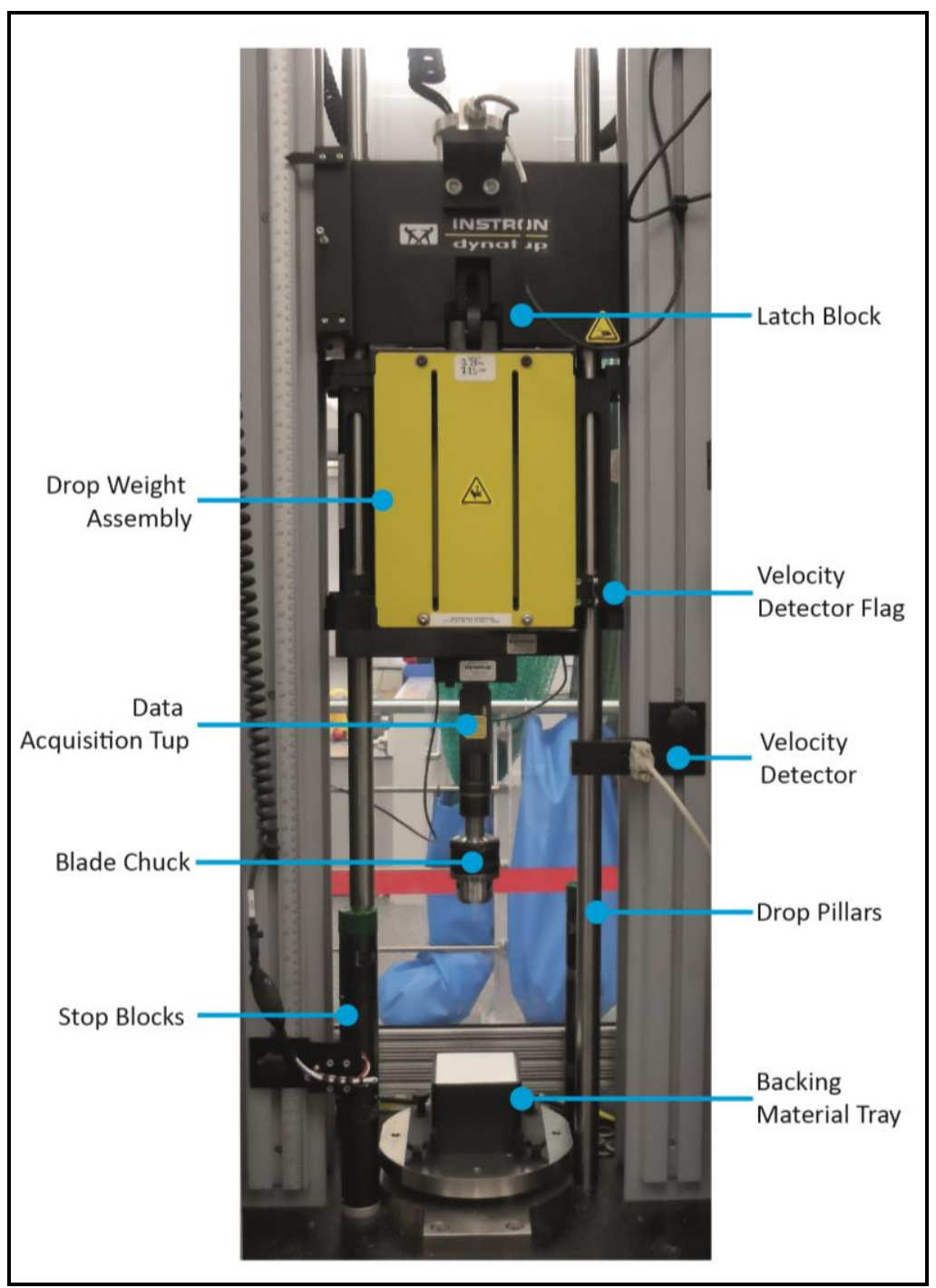

Figure 4: Instron 9250HV drop tower

The drop tower latch block was used to hoist the drop weight assembly to the required drop height. Once there the block was released allowing the weight and any 
attached articles, such as the data acquisition tup and the $6.50 \mathrm{~kg}$ calibrated blade chuck, to fall using the drop pillars as guides on to the test specimen inserted below. To validate the performance of each drop test, and to ensure the desired impact energy was reached, velocity detecting apparatus was utilised.

\subsubsection{Backing material}

To facilitate stab testing, Roma Plastilina ${ }^{\circledR}$ No. 1 clay was used as a backing material for all test specimens to be positioned upon - as defined by HOSDB body armour standards (Croft and Longhurst, 2007b; Croft, 2003). This clay was housed within a set of three steel fabricated trays - as shown within Figure 5.

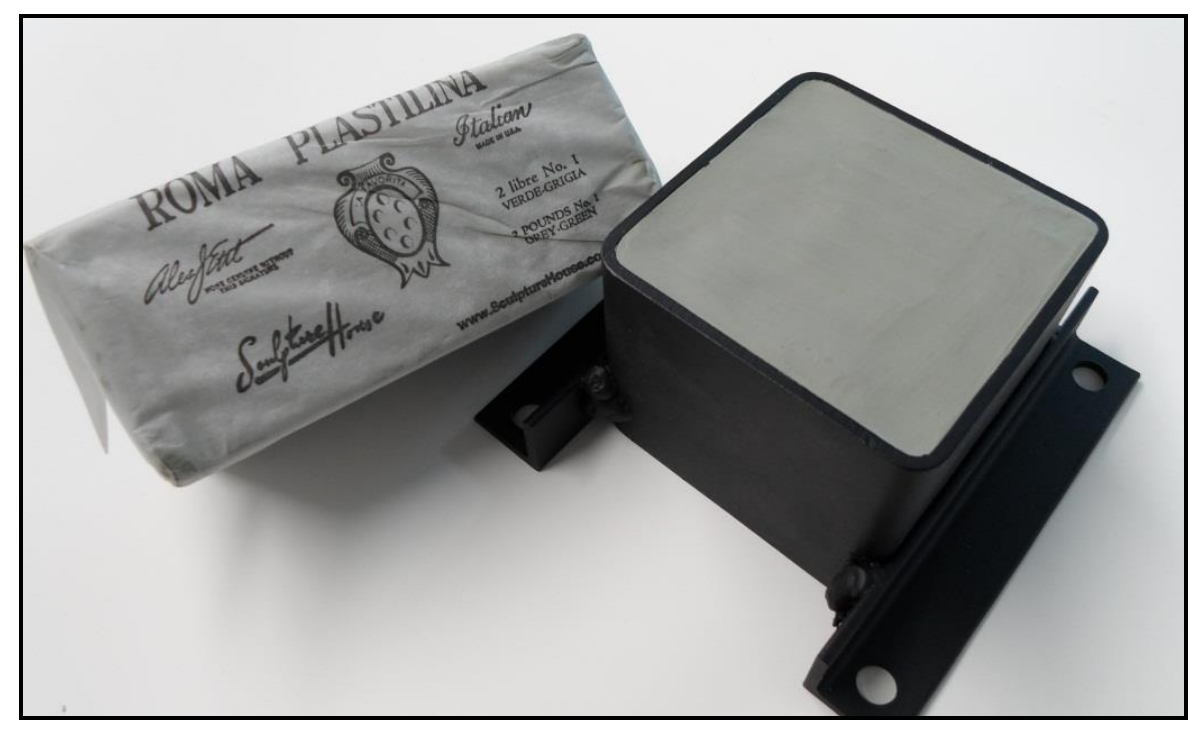

Figure 5: Roma Plastilina® No. 1 clay backing tray

Prior to experimentation, each backing tray was thermally conditioned at $30^{\circ} \mathrm{C}$ for a period of three hours using an Alpha $190 \mathrm{H}$ temperature chamber - in line with UK HOSDB 
body armour standards (Croft \& Longhurst, 2007a; Green, 1978). During testing the backing trays were temporarily secured to the bed of the drop tower, and rotated between each drop test.

\subsubsection{Test and environmental requirements}

All drop tests were performed to the UK HOSDB KR1-E1 impact energy of $24 \mathrm{~J}$, in an ambient environment within a temperature range of $21^{\circ} \mathrm{C}+/-6^{\circ} \mathrm{C}$, and a relative humidity range of 30-70\% (Croft \& Longhurst, 2007b). The experimental test requirements used on the Instron 9250HV drop tower are outlined within Table 2.

Table 2: Stab test experimental requirements

\begin{tabular}{cccccc}
\hline $\begin{array}{c}\text { Energy } \\
\text { Level }\end{array}$ & $\begin{array}{c}\text { Stab } \\
\text { Energy } \\
(\mathrm{Joule})\end{array}$ & $\begin{array}{c}\text { Drop } \\
\text { Mass } \\
(\mathrm{kg})\end{array}$ & $\begin{array}{c}\text { Drop } \\
\text { Height } \\
(\mathrm{m})\end{array}$ & $\begin{array}{c}\text { Drop } \\
\text { Velocity } \\
(\mathrm{m} / \mathrm{s})\end{array}$ & $\begin{array}{c}\text { Maximum Blade } \\
\text { Penetration } \\
(\mathbf{m m})\end{array}$ \\
\hline KR1-E1 & $24+/-0.5$ & 6.50 & 0.376 & 2.716 & 7.00 \\
\hline
\end{tabular}

\subsubsection{Test Blades}

One of the most common utility blades currently available, the Stanley 1992 trimming blade, was used during stab testing of the manufactured specimens. A specification summary of the Stanley blade is shown within Figure 6 . 


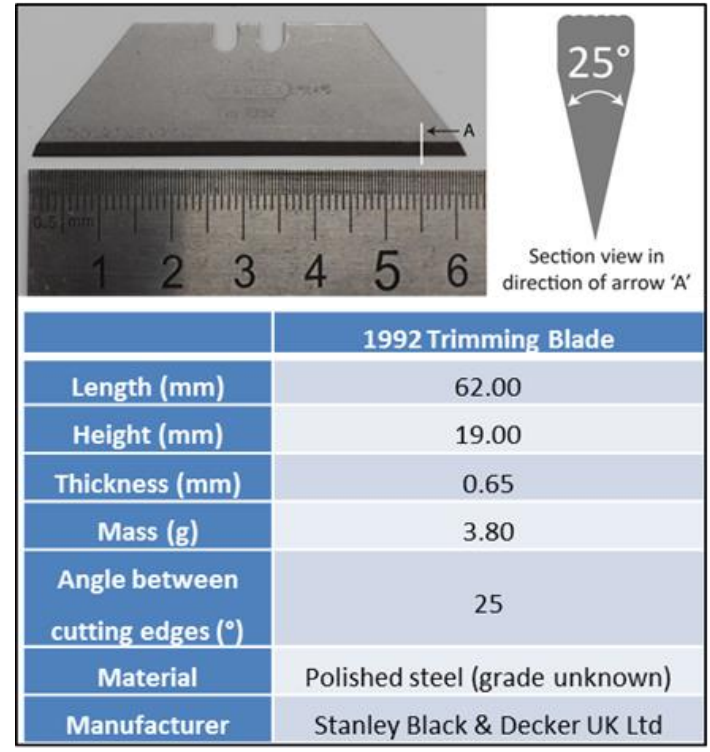

Figure 6: Stanley Tools 1992 trimming blade specification

A jig was used to securely fasten and orientate the test blade to ensure its double sided cutting edges contacted the strike surface of each test specimen (Johnson, 2014). Assembly of the blade to the drop tower chuck is shown within Figure 7.

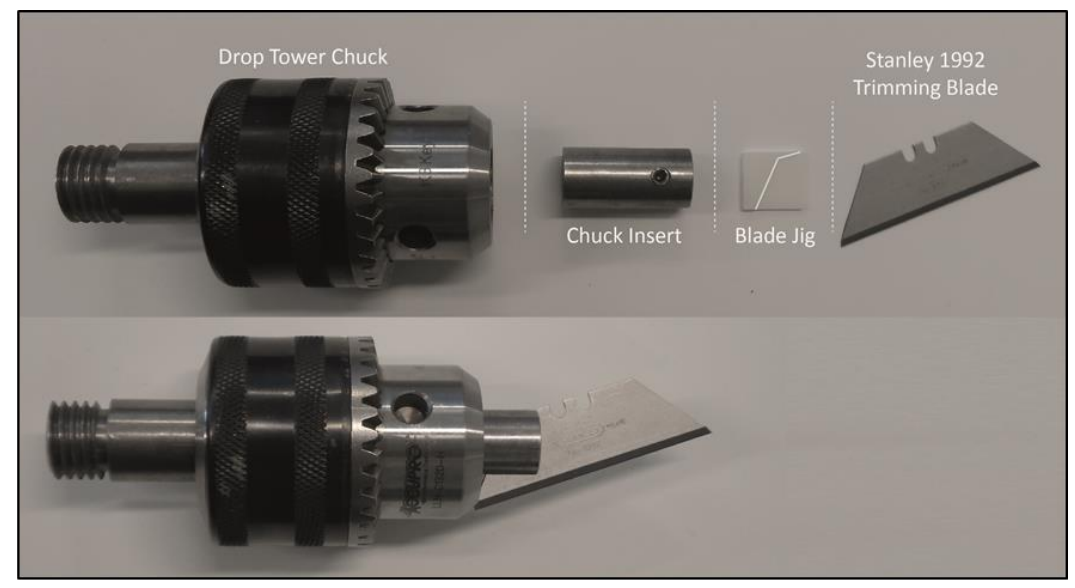

Figure 7: Test blade assembly 


\subsubsection{Recording blade penetration}

Any blade penetration through the underside of the test specimens were directly measured using digital callipers (Johnson, 2014) - as demonstrated within Figure 8.

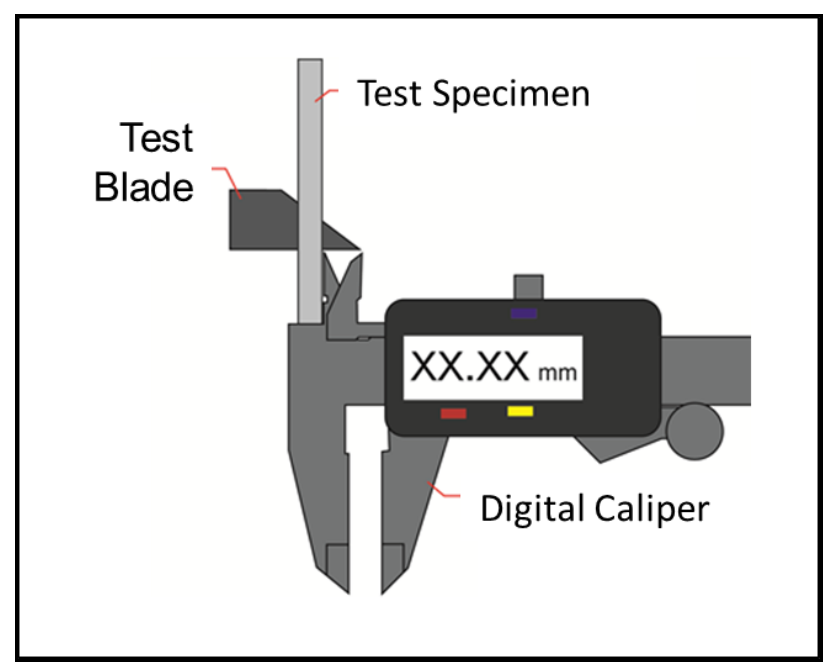

Figure 8: Measuring blade penetration

Further information relating to the manufacturing and test procedures used can be found within "Establishing design characteristics for the development of stab resistant Laser Sintered body armour" (Johnson, 2014). 


\section{Experimental results}

\subsection{Experiment one}

Results from this experiment demonstrated that successful and repeatable stab resistance was achieved with dual layered specimens with a minimum total thickness of $9.00 \mathrm{~mm}(2 \times 4.50$ mm planar specimens). A graphical overview of these results is shown within Figure 9.

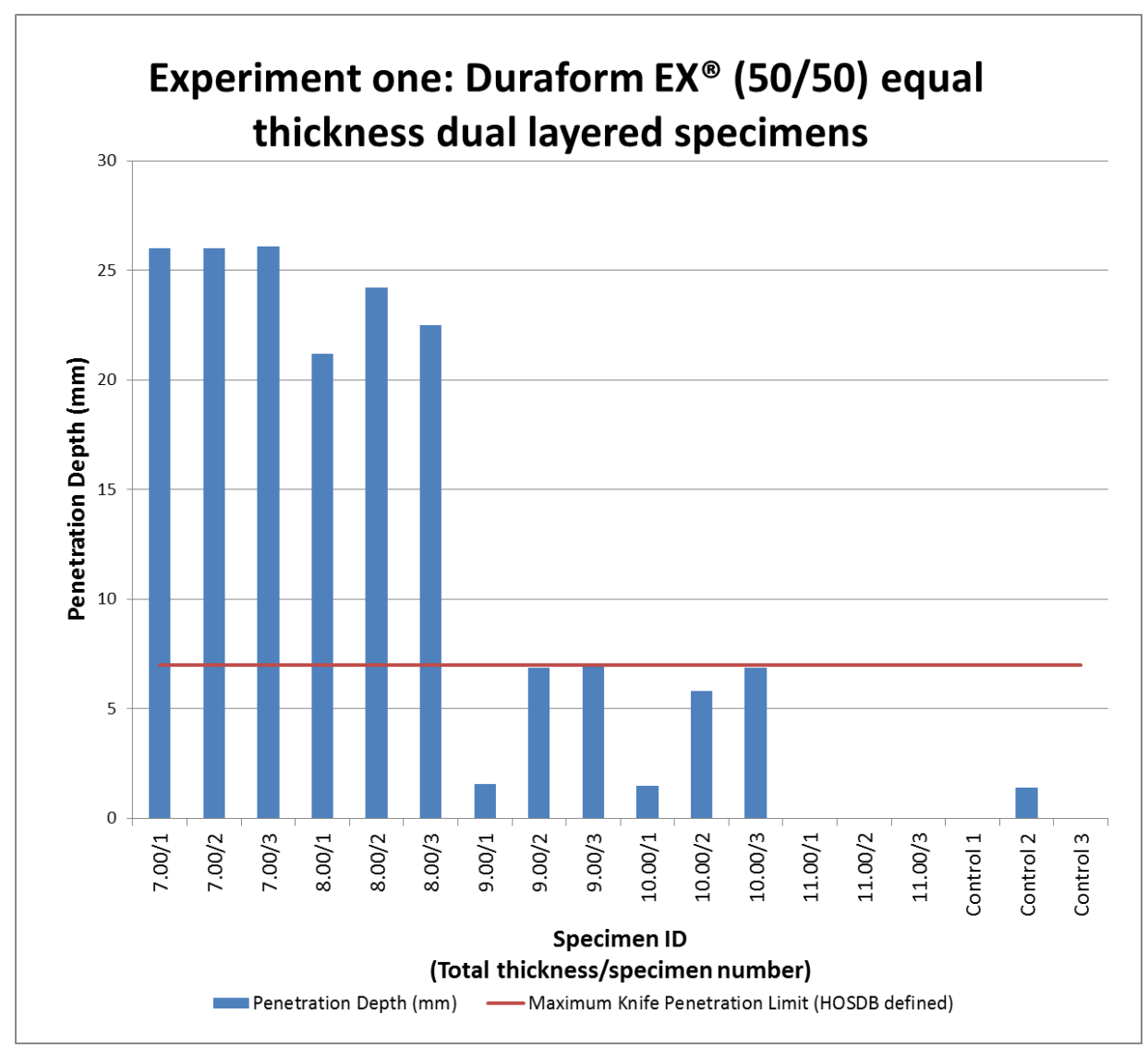

Figure 9: Duraform EX® (50/50) dual layered specimen Stab Test 
The maximum blade penetration across all three specimens was measured at $6.97 \mathrm{~mm}$ - with a mean penetration depth of $5.14 \mathrm{~mm}$. Figure 10 shows the maximum blade penetration demonstrated when testing the $9.00 \mathrm{~mm}$ dual layered specimens.

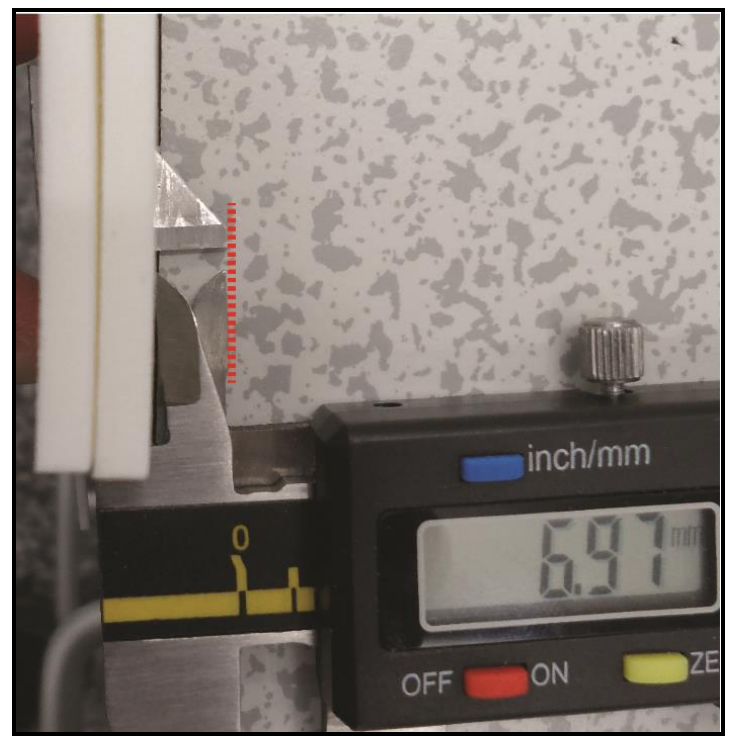

Figure 10: Maximum blade penetration across $9.00 \mathrm{~mm}$ thick dual layered specimens sintered from 50/50 mix Duraform EX®

A detailed overview of the measured blade penetration depths across all dual layered and single thickness (control) test specimens is shown within Table 3. 
Table 3: Duraform EX® (50/50) dual layered specimen detailed results

\begin{tabular}{c|c|c|c}
\hline No. & Specimen ID & $\begin{array}{c}\text { Penetration } \\
\text { Depth }(\mathbf{m m})\end{array}$ & Result \\
\hline $\mathbf{1}$ & $11.00 / 1$ Control & 0.00 & Pass \\
\hline $\mathbf{2}$ & $11.00 / 2$ Control & 1.39 & Pass \\
\hline $\mathbf{3}$ & $11.00 / 3$ Control & 0.00 & Pass \\
\hline $\mathbf{4}$ & $11.00 / 1$ & 0.00 & Pass \\
\hline $\mathbf{5}$ & $11.00 / 2$ & 0.00 & Pass \\
\hline $\mathbf{6}$ & $11.00 / 3$ & 0.00 & Pass \\
\hline $\mathbf{7}$ & $10.00 / 1$ & 1.47 & Pass \\
\hline $\mathbf{8}$ & $10.00 / 2$ & 5.80 & Pass \\
\hline $\mathbf{9}$ & $10.00 / 3$ & 6.86 & Pass \\
\hline $\mathbf{1 0}$ & $9.00 / 1$ & 1.57 & Pass \\
\hline $\mathbf{1 1}$ & $9.00 / 2$ & 6.87 & Pass \\
\hline $\mathbf{1 2}$ & $9.00 / 3$ & 6.97 & Pass \\
\hline $\mathbf{1 3}$ & $8.00 / 1$ & 21.18 & Fail \\
\hline $\mathbf{1 4}$ & $8.00 / 2$ & 24.23 & Fail \\
\hline $\mathbf{1 5}$ & $8.00 / 3$ & 22.52 & Fail \\
\hline $\mathbf{1 6}$ & $7.00 / 1$ & 26.00 & Fail \\
\hline $\mathbf{1 7}$ & $7.00 / 2$ & 26.00 & Fail \\
\hline $\mathbf{1 8}$ & $7.00 / 3$ & 26.09 & Fail \\
\hline Mean Impact Energy $(\mathbf{J})$ & \multicolumn{2}{|c}{23.67} \\
\hline Mean Impact Velocity $(\mathbf{m} / \mathbf{s})$ & & 2.70 \\
\hline
\end{tabular}

Test results also demonstrated that all three of the $11.00 \mathrm{~mm}$ single thickness control specimens provided a successful level of blade penetration resistance. Specimens with a total thickness below $9.00 \mathrm{~mm}$ demonstrated blade penetration in excess of $20.00 \mathrm{~mm}$ - far beyond the HOSDB $7.00 \mathrm{~mm}$ permissible limit. In fact, the $7.00 \mathrm{~mm}$ thick dual layered specimens demonstrated no resistance to the stab threat, as the maximum level of blade penetration was witnessed across all three tests. In these test instances the mechanical stops on the drop tower prevented the blade from puncturing any further. 
Although the results documented within this experiment demonstrated a dual layer thickness totalling $9.00 \mathrm{~mm}$ provided successful levels of stab protection, uncertainty remained as to whether stab protection could be maintained where a dual layered structure of varying thickness elements would be utilised. Therefore the proceeding experiment was performed to investigate such.

\subsection{Experiment two}

An overview of the blade penetration results from the stab testing of the multi-thickness dual layered specimens with a total thickness of 9.00 is shown within Figure 11.

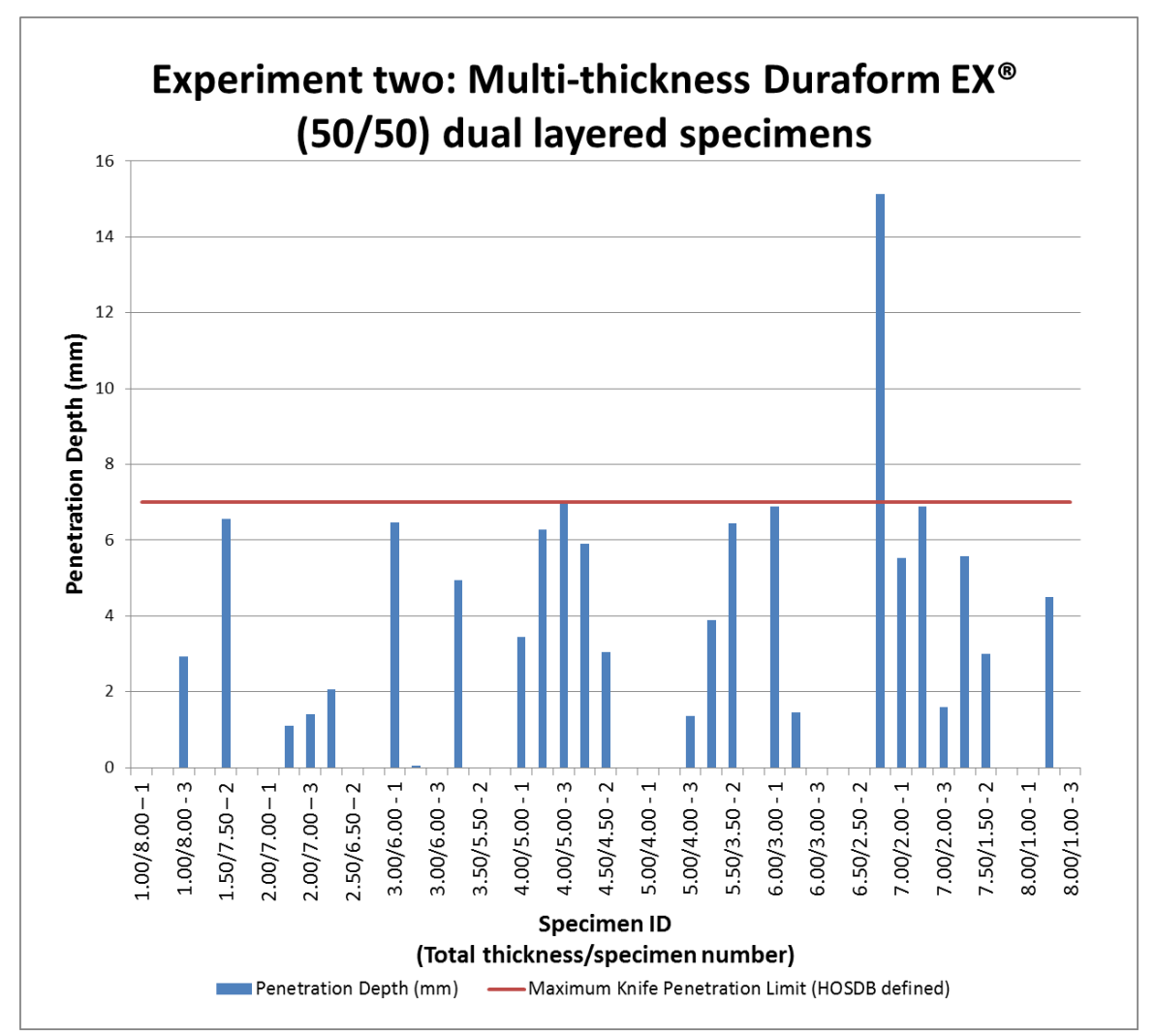

Figure 11: Multi-thickness Duraform EX® (50/50) dual layered specimen results overview 
44 of the 45 samples tested within this second experiment demonstrated successful levels of stab resistance within established HOSDB KR1-E1 requirements. As highlighted within Table 4, one specimen with a layer arrangement of $6.50 / 2.50 \mathrm{~mm}$ failed to provide suitable stab protection.

Table 4: Experiment two results detailed overview

\begin{tabular}{c|c|c|c}
\hline Test & \multicolumn{1}{c}{ Specimen ID } & \multicolumn{1}{c}{$\begin{array}{c}\text { Penetration } \\
\text { Depth }(\mathbf{m m})\end{array}$} & Result \\
\hline $\mathbf{1}$ & $1.00 / 8.00-1$ & 0.00 & Pass \\
\hline $\mathbf{2}$ & $1.00 / 8.00-2$ & 0.00 & Pass \\
\hline $\mathbf{3}$ & $1.00 / 8.00-3$ & 2.94 & Pass \\
\hline $\mathbf{4}$ & $1.50 / 7.50-1$ & 0.00 & Pass \\
\hline $\mathbf{5}$ & $1.50 / 7.50-2$ & 6.57 & Pass \\
\hline $\mathbf{6}$ & $1.50 / 7.50-3$ & 0.00 & Pass \\
\hline $\mathbf{7}$ & $2.00 / 7.00-1$ & 0.00 & Pass \\
\hline $\mathbf{8}$ & $2.00 / 7.00-2$ & 1.11 & Pass \\
\hline $\mathbf{9}$ & $2.00 / 7.00-3$ & 1.40 & Pass \\
\hline $\mathbf{1 0}$ & $2.50 / 6.50-1$ & 2.06 & Pass \\
\hline $\mathbf{1 1}$ & $2.50 / 6.50-2$ & 0.00 & Pass \\
\hline $\mathbf{1 2}$ & $2.50 / 6.50-3$ & 0.00 & Pass \\
\hline $\mathbf{1 3}$ & $3.00 / 6.00-1$ & 6.46 & Pass \\
\hline $\mathbf{1 4}$ & $3.00 / 6.00-2$ & 0.05 & Pass \\
\hline $\mathbf{1 5}$ & $3.00 / 6.00-3$ & 0.00 & Pass \\
\hline $\mathbf{1 6}$ & $3.50 / 5.50-1$ & 4.94 & Pass \\
\hline $\mathbf{1 7}$ & $3.50 / 5.50-2$ & 0.00 & Pass \\
\hline $\mathbf{1 8}$ & $3.50 / 5.50-3$ & 0.00 & Pass \\
\hline $\mathbf{1 9}$ & $4.00 / 5.00-1$ & 3.44 & Pass \\
\hline $\mathbf{2 0}$ & $4.00 / 5.00-2$ & 6.27 & Pass \\
\hline $\mathbf{2 1}$ & $4.00 / 5.00-3$ & 6.98 & Pass \\
\hline $\mathbf{2 2}$ & $4.50 / 4.50-1$ & 5.91 & Pass \\
\hline $\mathbf{2 3}$ & $4.50 / 4.50-2$ & 3.05 & Pass \\
\hline & & & \\
\hline
\end{tabular}

\begin{tabular}{c|c|c|c}
\hline Test & \multicolumn{1}{c}{ Specimen ID } & \multicolumn{1}{c}{$\begin{array}{c}\text { Penetration } \\
\text { Depth }(\mathbf{m m})\end{array}$} & Result \\
\hline $\mathbf{2 4}$ & $4.50 / 4.50-3$ & 0.00 & Pass \\
\hline $\mathbf{2 5}$ & $5.00 / 4.00-1$ & 0.00 & Pass \\
\hline $\mathbf{2 6}$ & $5.00 / 4.00-2$ & 0.00 & Pass \\
\hline $\mathbf{2 7}$ & $5.00 / 4.00-3$ & 1.36 & Pass \\
\hline $\mathbf{2 8}$ & $5.50 / 3.50-1$ & 3.89 & Pass \\
\hline $\mathbf{2 9}$ & $5.50 / 3.50-2$ & 6.44 & Pass \\
\hline $\mathbf{3 0}$ & $5.50 / 3.50-3$ & 0.00 & Pass \\
\hline $\mathbf{3 1}$ & $6.00 / 3.00-1$ & 6.89 & Pass \\
\hline $\mathbf{3 2}$ & $6.00 / 3.00-2$ & 1.46 & Pass \\
\hline $\mathbf{3 3}$ & $6.00 / 3.00-3$ & 0.00 & Pass \\
\hline $\mathbf{3 4}$ & $6.50 / 2.50-1$ & 0.00 & Pass \\
\hline $\mathbf{3 5}$ & $6.50 / 2.50-2$ & 0.00 & Pass \\
\hline $\mathbf{3 6}$ & $6.50 / 2.50-3$ & 15.14 & Fail \\
\hline $\mathbf{3 7}$ & $7.00 / 2.00-1$ & 5.53 & Pass \\
\hline $\mathbf{3 8}$ & $7.00 / 2.00-2$ & 6.89 & Pass \\
\hline $\mathbf{3 9}$ & $7.00 / 2.00-3$ & 1.59 & Pass \\
\hline $\mathbf{4 0}$ & $7.50 / 1.50-1$ & 5.58 & Pass \\
\hline $\mathbf{4 1}$ & $7.50 / 1.50-2$ & 3.01 & Pass \\
\hline $\mathbf{4 2}$ & $7.50 / 1.50-3$ & 0.00 & Pass \\
\hline $\mathbf{4 3}$ & $8.00 / 1.00-1$ & 0.00 & Pass \\
\hline $\mathbf{4 4}$ & $8.00 / 1.00-2$ & 4.49 & Pass \\
\hline $\mathbf{4 5}$ & $8.00 / 1.00-3$ & 0.00 & Pass \\
\cline { 1 - 2 } & & &
\end{tabular}


Such may be regarded as an anomaly as the two additional specimens within this multi-thickness group demonstrated zero blade penetration. Upon further analysis of the results attained within experiment two, mean blade penetration was recorded to be lower when the top layer of the dual layered specimens ranged between $1.00 \mathrm{~mm}$ to $3.50 \mathrm{~mm}$ thick. Once the top layer of the two layered structure became the greater thickness, the results suggest that mean blade penetration increased - as presented within Figure 12.

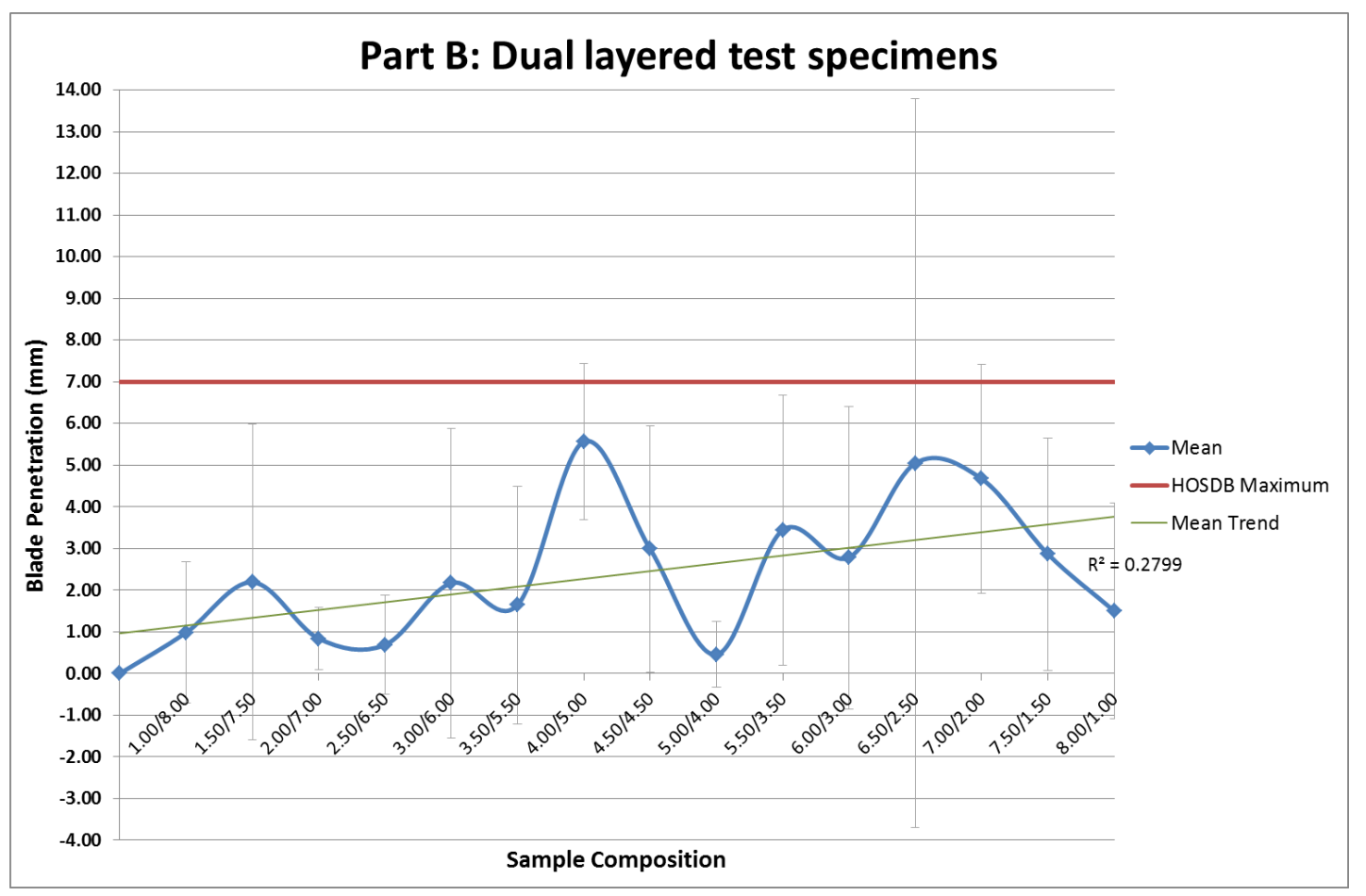

Figure 12: Experiment two - mean blade penetration per dual layered composition group

This occurrence is also illustrated within Figure 13 where the thinner top layer of the 1.00/8.00-2 test specimen deformed under impact of the blade and therefore presented no 
blade penetration, while the 7.00/2.00-2 specimen featuring the thicker top layer demonstrated blade penetration measuring $6.89 \mathrm{~mm}$ - within permissible limits.
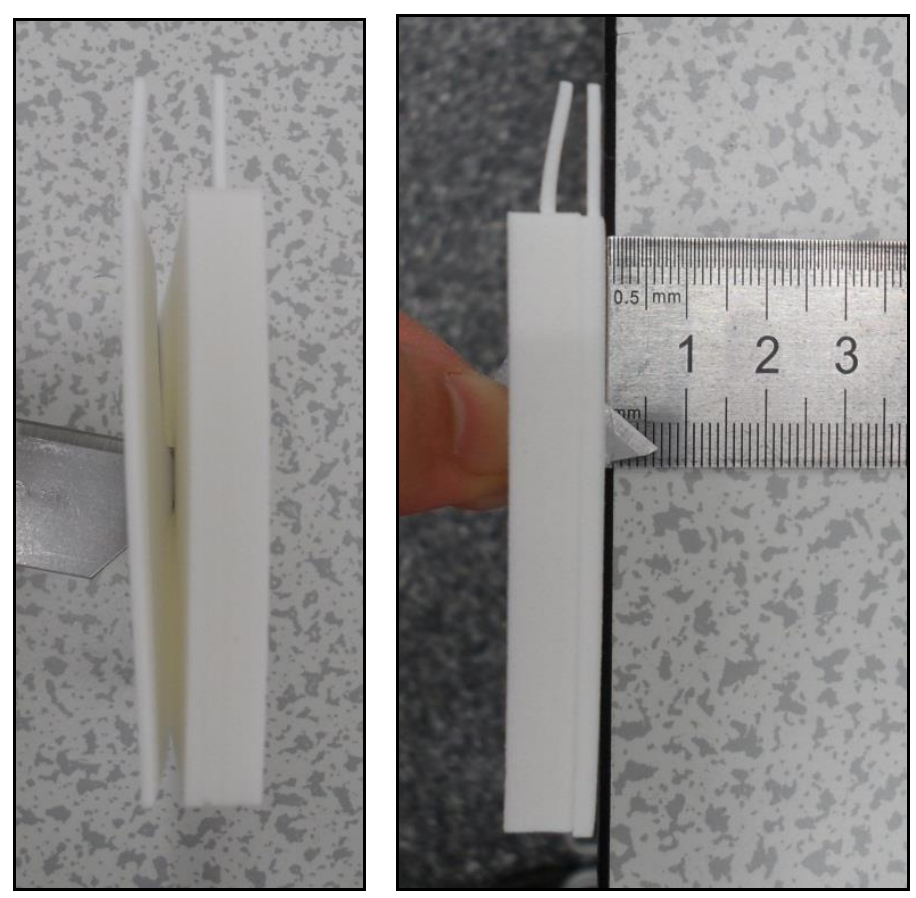

Figure 13: Specimen 1.00/8.00-2 (left) \& Specimen 7.00/2.00-2 manufactured from 50/50 mix Duraform EX® (right) 


\section{Conclusions}

A significant reduction in the total specimen thickness required to achieve successful stab resistance to the UK HOSDB KR1-E1 standard was successfully demonstrated within this body of work.

Previously established research demonstrated a minimum single thickness of 11.00 mm was required with specimens Laser Sintered from a 50/50 mix of Duraform EX® powder. However, this body of work demonstrated that through the adoption of a suitable build material and a two layered sacrificial protection system, typically found within naturally occurring protective solutions, the minimum required total thickness can be reduced to $9.00 \mathrm{~mm}$. With regards to the build material, previous research has demonstrated that enhanced mechanical performance may be attributed to the increased molecular weight of the recycled powder element within the Duraform EX® 50/50 mix due to prior thermal loading (Gibson et al., 2010; Zarringhalam, 2007).

Whilst maintaining the minimum dual layer total thickness of $9.00 \mathrm{~mm}$, additional investigation within Experiment two demonstrated that the composition of the dual layer structures used to generate the minimum total thickness had a minor effect on stab resistive performance. A general trend was observed, where specimens featuring a thin top layer demonstrating a lower level of blade penetration in comparison to specimens with a thick top layer. While such a trend was observed, all specimens demonstrated stab protection within acceptable parameters. This development therefore suggested that geometrically complex components featuring a dual layered structure, that also satisfies the $9.00 \mathrm{~mm}$ minimum 
thickness requirement, could provide an appropriate level of stab-protection to the KR1-E1 stab impact energy.

Although the anomalous result presented within 'Test 36' of Experiment two was measured to be beyond the permissible level of blade penetration as determined by the HOSDB, it should be noted that the remaining $98 \%$ of specimens of the same total thickness provided appropriate protection. Even so, further investigation would be required to ensure all tested specimens could provide protection once adapted into a wearable body armour garment. Potential explanations for the anomalous result experienced include manufacturing faults within the specimens, or a higher level of blade sharpness with the specific test blade used.

A brief summary of the results obtained within these experiments to achieve successful stab resistance to HOSDB KR1-E1 requirements, using a dual layered structure manufactured from a 50/50 mix of Duraform EX® LS powder are presented within Table 5.

Table 5: Summary of dual thickness stab resistant requirements

\begin{tabular}{cccc}
\hline $\begin{array}{c}\text { Experiment } \\
\text { No. }\end{array}$ & $\begin{array}{c}\text { Total } \\
\text { Thickness }\end{array}$ & $\begin{array}{c}\text { Top Layer } \\
\text { Thickness }\end{array}$ & $\begin{array}{c}\text { Bottom Layer } \\
\text { Thickness }\end{array}$ \\
\hline $\mathbf{1}$ & $9.00 \mathrm{~mm}$ & 4.50 & 4.50 \\
$\mathbf{2}$ & $9.00 \mathrm{~mm}$ & $\begin{array}{c}\text { Layers ranged in thickness from } 1.00 \text { to } 8.00 \\
\text { mm thick in } 0.5 \text { mm increments. All } \\
\text { specimens with total thickness of } 9.00 \mathrm{~mm} \\
\text { successful. }\end{array}$ \\
\hline
\end{tabular}


The successful results attained can be used to facilitate the practical application and development of articulated LS stab resistant body armour - with further weight reductions possible through the minimisation of armour thickness via the adoption of a layered protective structure.

Beyond this body of work, the results further support existing literature that layered structures offer protective benefits over those of a single thickness. This may therefore suggest that rigid armour manufactured via traditional manufacturing processes could potentially benefit from a multi-layered design approach. However, to confirm such further investigation beyond the scope of this research would be required. 


\section{Further work}

This research presented here forms part of a larger-scale study of the use of Laser Sintering for the production of personalised body armour. Ongoing research activities within this field of work include:

1. Establish design characteristics for the formation of an articulated protective garment and associated linkable geometries.

2. Other LS materials and post-processing activities on the protective and operational performance of Laser Sintered armour.

3. Methodology for establishing bespoke/made-to-measure armour.

4. Feasibility of use for high levels of stab, spike, and blunt force threats.

5. Methods to enhance protective performance via the adoption of post-processing activities. 


\section{References}

Ashdown, C., 1909. British and foreign arms \& armour, Library. TC \& EC Jack, London.

Ben-Dor, G., Dubinsky, A., Elperin, T., 2010. Effect of layering on ballistic properties of metallic shields against sharp-nosed rigid projectiles. Eng. Fract. Mech. 77, 2791-2799. doi:10.1016/j.engfracmech.2010.05.004

Bingham, G., Paterson, A., Bibb, R., Johnson, A., 2013. The Design and Modelling of Additive Manufactured Textiles Structures and Garments, in: The 1st International Conference on Digital Fashion.

Continuum Fashion, 2011. N12 Bikini [WWW Document]. URL http://www.continuumfashion.com/N12.html (accessed 12.15.11).

Croft, J., 2003. PSDB Body Armour Standards for UK Police. Crown, United Kingdom.

Croft, J., Longhurst, D., 2007a. HOSDB Body Armour Standards for UK Police (2007) Part 3: Knife and Spike Resistance - 39/07/C. Crown, United Kingdom.

Croft, J., Longhurst, D., 2007b. HOSDB Body Armour Standards for UK Police (2007) Part 2: Ballistic Resistance. Crown, United Kingdom.

Dempsey, P., Handcock, P., Rehrer, N., 2013. Impact of police body armour and equipment on mobility. Appl. Ergon. 1-5. doi:10.1016/j.apergo.2013.02.011

Gibson, I., Rosen, D., Stucker, B., 2010. Additive Manufacturing Technologies. Springer, New York. doi:10.1007/978-1-4419-1120-9

Green, M., 1978. Stab Wound Dynamics - A Recording Technique for Use in Medico-Legal Investigations. J. Forensic Sci. Soc. 18, 161-163.

Johnson, A., 2014. Establishing design characteristics for the development of stab resistant Laser Sintered body armour. PhD Thesis. Loughborough Design School. Loughborough University.

Johnson, A., Bingham, G., Majewski, C., 2012. Establishing the performance requirements for stab resistant Additive Manufactured Body Armour (AMBA). 23rd Annu. Int. Solid Free. Fabr. Symp. - An Addit. Manuf. Conf. SFF 2012 297-306.

Johnson, A., Bingham, G., Wimpenny, D., 2013. Additive manufactured textiles for highperformance stab resistant applications. Rapid Prototyp. J. 19, 199-207. doi:10.1108/13552541311312193 
Kaiser, R., 2013. Cut-Tex® PRO - The World's Best Cut Resistant Fabric [WWW Document]. URL http://www.ppss-group.com/blog/cut-tex-pro-cut-resistant-fabric/ (accessed 7.4.14).

Krassenstein, B., 2015. 20,000 3D Printed Parts Are Currently Used on Boeing Aircraft as Patent Filing Reveals Further Plans [WWW Document]. Online. URL http://3dprint.com/49489/boeing-3d-print/ (accessed 8.16.15).

Scott, R., 2005. Textiles for protection. Woodhead Publishing Limited, Cambridge.

Teng, X., Wierzbicki, T., Huang, M., 2008. Ballistic resistance of double-layered armor plates. Int. J. Impact Eng. 35, 870-884. doi:10.1016/j.ijimpeng.2008.01.008

Zarringhalam, H., 2007. Investigation into Crystallinity and Degree of Particle Melt in Selective Laser Sintering. PhD Thesis, Wolfson School of Mechanical and Manufacturing Engineering, Loughborough University.

Zhu, D., Ortega, C., Motamedi, R., Szewciw, L., Vernerey, F., Barthelat, F., 2012. Structure and Mechanical Performance of a "Modern" Fish Scale. Adv. Eng. Mater. 14, B185B194. doi:10.1002/adem.201180057 